\title{
Why They Lie: Probing the Explanations for Journalistic Cheating
}

\author{
Ivor Shapiro \\ Ryerson University
}

The Fabulist: A Novel. By Stephen Glass. New York: Simon \& Schuster, 2003. 339 pp. ISBN 0743227123.

Burning Down My Master's House: My Life at the New York Times. By Jayson Blair. Beverly Hills, CA: New Millennium Press, 2004. 288 pp. ISBN 193240726X.

Hard News: The Scandals at the New York Times and Their Meaning for American Media. By Seth Mnookin. New York: Random House, 2004. 352 pp. ISBN 1400062446.

The Cheating Culture: Why More Americans Are Doing Wrong to Get Ahead. By David Callahan. Orlando, FL: Harcourt, 2004. 353 pp. ISBN 0156030055.

Suddenly, they're everywhere. A Halifax-based stringer for the Boston Globe fabricates graphic details of a seal hunt that, unbeknownst to her, was postponed. A staff member of the Ottawa Citizen apologizes and loses his position on the editorial board after being caught in plagiarism. The National Post hires a sportswriter recently fired for plagiarism at the Winnipeg Free Press. Harper's magazine editor Lewis Lapham and syndicated author Mitch Albom write details about things yet to happen, in the past tense. The Washington bureau chief for the Associated Press is fired for fabricating experts and organizations. The Iowa State Daily publishes material lifted from the Minneapolis Star Tribune. North American newspapers hit with cheating scandals in this very young century, and the sometimes storied names of the perpetrators, have included the New York Times (Jayson Blair, Michael Finkel, Rick Bragg), the Toronto Star (Prithi Yelaja), USA Today (Jack Kelley), the National Post (Brad Evenson, Elizabeth Nickson, Gillian Cosgrove), and the Boston Globe (Mike Barnicle).

Or maybe what's sudden is the cheaters are getting caught. The Internet helps, of course: if you think you've seen a passage somewhere before, it's no longer hard work to find the smoking gun of plagiarism. And it's become more likely that someone who knows something about a story for which a reporter has fabricated details will actually see the story, recognize the lie, and maybe expose it.

You'd think this ever-present e-danger, and the frequent stories of disgrace, would put the fear of God into journalists. But (judging by the pace of new scandals), the cheaters carry on undaunted. So the question becomes: Why do they do it? Why does dishonesty thrive?

Ivor Shapiro is an Assistant Professor in the School of Journalism at Ryerson University, 350 Victoria Street, Toronto, ON M5B 2K3. E-mail: ishapiro@ryerson.ca.

Canadian Journal of Communication, Vol 31 (2006) 261-266

(C)2006 Canadian Journal of Communication Corporation 
A good explanation will be complex, not simple. It's not enough to blame naked ambition: Jayson Blair was scarcely the only ambitious reporter at the New York Times, and no one says they're all cheating — but the New York Times published corrections and plagiarism notes for 39 stories by Blair in one black day, May 11, 2003. Nor is the problem a lack of ability. Stephen Glass proved himself a more than gifted writer and brilliant reporter at several leading magazines before The New Republic retracted 27 of Glass' 41 pieces because of fabrication and plagiarism.

It's not only their status (along with Kelley) as serial fabricators that distinguishes Blair and Glass from others in the hall of shame. Uniquely, these two forever-former reporters proceeded to write their own stories and offer explanations for their conduct. To try making sense of the apparent epidemic of cheating, one might as well begin there-with a look at what these two cheaters par excellence have to say for themselves.

Perhaps unsurprisingly, Glass chose to use the form of fiction to suggest that he was now telling the truth about lying before. The Fabulist is therefore an odd hybrid of suggested facts and acknowledged fictions, whose central character (named Stephen Glass) is, for the casual reader and viewer, barely distinguishable from the anti-hero of the 2003 film Shattered Glass. (The film, in turn, is a kind of docudrama account of the scandal that veers into fiction whenever this becomes narratively convenient, all of which makes one wonder whether the apparent inability of today's storytellers to decide whether they are fiction writers or journalists and historians might have something to do with the similar confusion that journalism is producing in its readers.)

The Fabulist drips with self-justification and self-pity: "I can't have any more people hate me ... I'm sorry. I am truly sorry, I'm sorry ...," its protagonist tells a telephone operator at one point before crying himself to sleep (p. 124). But the novel does clearly, and certainly intentionally, suggest explanations for Glass' actions.

These include personal factors that we might place under the heading of psychological disability: "Glass" is presented as a "fucked-up kid" who is so "compulsively imaginative" that he's surprised to discover that notes for his fabricated stories don't exist. He longs to be admired and loved; he cheats to avoid rejection. But the author also points a stern finger of blame at workplace pressures: in the fictional "Glass" " first flirtation with fabrication, the celebrated but professionally untrained star pitches a story to his colleagues, fails to find reportable facts that live up to what was promised, then faces pressure from editors to provide more details - and, after that, more stories like it. He finds himself increasingly encouraged to write "snarky, glib, superior" copy and learns that what a journalist is looking for is "a good story; accuracy's only half of it" (pp. 181-185). None of this kind of pressure will be foreign to true-life feature writers in positions comparable to Glass'.

The real Glass gave an interview to CBS-TV's 60 Minutes while promoting the book. In it, he described a decisive moment of temptation that will resonate for 
journalists everywhere: "I remember thinking, if I just had the exact quote that I wanted, it would be perfect ...." It's what he did next that sets him apart:

[A]nd then I wrote something on my computer and I let it stand. And then it ran in the magazine and I said to myself what I said every time, 'You must stop . . . . B But I didn't . . . . I loved the electricity, I loved going to story conference meetings and telling people what my story was going to be and seeing them in front of me, excited. I wanted every story to be a home run.

Unlike Glass' “novel," Blair's Burning Down My Master's House declares itself pure memoir. That is, factual. Of course, no one would take this author's idea of truth for granted, and several relatively benign lies have been identified in it. Stylistically and in overall content, the book is far from a page-turner even for media junkies: the New Yorker's reviewer, Nicholas Lemann, described it as "a curio, an artifact, an unprocessed download from Blair's brain - vivid, wired, serviceably written and paced, and, in a way, more interesting for its artlessness." But, like Glass', Blair's account presents an interesting combination of explanations for journalistic sins.

These explanations are not always explicit, coherent, or clear, but they start (once again) with personal factors: childhood sexual abuse, manic depression, cocaine addiction, excessive drinking, even a touch of post-traumatic stress disorder. Blair, who is Black, also imputes racism to certain colleagues and managers. But the implied explanations include, once again, mostly plausible references to the pressures attached to working in a high-profile journalistic workplace - a constant pressure to produce, "a deep desire to get into the paper," and, especially, to make the front page, the ultimate, though fleeting, measure of a reporter's worth.

Newsweek media writer Seth Mnookin covered the Blair story for his magazine. His book, Hard News, provides a sometimes tedious blow-by-blow account of the Times' annus horribilus and surprisingly little substance to the promised analysis of its "meaning" for journalism. Former Times executive editor Howell Raines is the uncontested bad guy of this book, which doesn't mesh well with Mnookin's own reporting of how Blair became Blair (cheating at high school and at the University of Maryland's journalism school). Though the tick-tock account of how the Times scandals evolved will enthrall only insiders and voyeurs with more than the average reader's interest in the inner working of the Times, there are some compelling scenes, including an astonishing Raines-as-Captain-Queeg moment of almost psychotic paranoia (p. 203).

As for an explanation for the cheating, Mnookin's is clearly the dysfunctional work culture of the Raines-led Times (although Mnookin refers to Blair unequivocally as a "sociopath" at least twice, which, if true, would be some kind of explanation in itself). Race, he adds carefully, comes into it: "Blair's career at the Times had undeniably been shaped by his race - he'd initially been recruited into a minority internship program - but the vagaries of his career under Howell Raines' tenure had more to do with the favoritism and factionalism that had gripped the paper" (p. 176). It's true that affirmative action helped Blair get, and 
probably keep, his job at the Times, but reporters have won jobs through preference both principled and prejudicial since the dawn of the craft without journalism's worst sins being attributed to those factors. Similarly, there's been cheating at far too many news organizations to blame the man who happened to be executive editor at one. More inherently persuasive would be explanations that point to patterns of events and circumstances.

One such pattern could be the rising value given to narrative detail and storytelling values in today's reporting. Glass' stories were rich in the kind of vivid, unattributed details that his colleagues, bosses, and readers loved - details that were too good to be true. He was hardly the first reporter to allow narrative to trump facts: others have included freelancer Michael Finkel, who, until his disgrace over a November 2001 New York Times Magazine cover story that turned out to be a composite, took pride in never using a tape recorder or notepad during an interview. (Other dedicated practitioners of literary journalism who feel the same way include, famously, Gay Talese.)

But narrative ambitions are only part of a story that might have a lot more to do with a sweeping problem identified by Margaret Jones Patterson and Steve Urbanski (2004). The two Duquesne University researchers compared accounts of the Blair affair to the most famous prior case of journalistic fabrication, that of the Washington Post's Janet Cooke, who was forced to return her Pulitzer Prize in 1981 after confessing that its heroin-addicted eight-year-old protagonist was a composite character. Patterson and Urbanski's conclusion: problems with fact arise when newspapers' managers lose sight of their fundamental mission. Accounts of both scandals revealed common "decision-making turning points" regarding managers' choices on whether or not to pass along warnings about reporters' behaviour, to check anonymous sources, and to give serious attention to allegations of fabrication and plagiarism. Journalists in key positions (not just the two disgraced reporters) failed to "measure their decisions and actions against their mission as a public trust" and a commitment to truth as a primary value. Instead, these decision-makers were "blinded by journalism's lesser values," meaning career ambitions and "the thrill of getting a good story."

For David Callahan, even that sweeping explanation-a distorted culture within the newspaper-is not broad enough. Callahan's The Cheating Culture suggests that lying and stealing are epidemic, inevitable, and well rewarded throughout U.S. society. (And his description of a culture that winks at dishonesty, when it doesn't actually smile on it, does not feel alien to Canadian eyes.) The book is part encyclopedia of deceit and part tour of the corporate underbelly; its central thesis is that modern citizens have developed "two moral compasses." Although normal morality may prevail in private life, unfettered ambition drives decisions involving money or career, and survival-of-the-fittest reality TV is an apt paradigm for it.

Cheating is no longer seen as a real sin, Callahan argues: instead, there's a sense that "everyone does it," and there's no longer a point in obeying the rules. Financial pressure spurs cheating: when an auto-repair chain demands and 
rewards higher productivity from its line managers, customers start paying for labour and parts they didn't need. The cheating culture ascends when society is divided into a "winning class" and an "anxious class" - and the winners' success stories send a clear signal that cutting corners gets you an edge.

Turning his gaze briefly on journalism, Callahan attributes the Blair and Glass scandals to "the reaping of big rewards" that come with big success in the "star system" that divides highly paid media elites from poorly paid ordinary achievers. True, Callahan tends to fit every last cheater in his book into a template in which the rich and the right are to blame for all wrong. And the book's evidence consists far too heavily of polling data, which is by its nature dubious proof for anything.

But it's hard to deny that increasing workload, and pressure to produce, are apt to draw out the cheater within a human being. And Callahan is surely right to locate journalism's problems within a wider culture. If "everyone" is doing it, why would we expect journalists to be different? Indeed, we should expect journalists - without professional restraints, and, let's face it, with an instinct as a group for breaking rules - to be worse!

A good case can be made that in journalism, at least, "everyone" has been doing it for many years. Jack Shafer, media critic of the online magazine Slate, points out that legendary figures such as H. L. Mencken, A. J. Liebling, and Joseph Mitchell all confessed to fabricating (Shafer, 2003). If so, it's odd that managers seem to trust so readily the journalists who report to them - and even to ignore the doubts that are raised from time to time, as in the Glass, Blair, Kelley, and Cooke cases before the scandals broke. As Patterson and Urbanski write: "Once [Blair and Cooke] had been accepted into their respective organizations, they apparently sized up the holes in the journalistic gatekeeping system and gambled that they could sneak through" (2004, p. 12).

Misplaced trust could turn out to be the most remediable cause of the cheating problem, and some respected (though still relatively isolated) voices are calling for an end to the presumption of innocence. Here's Mnookin: "It's up to the journalistic community to begin better policing itself" (p. 239). Here's Samuel G. Freedman: "All reputable journalists, leaders of news organizations and publishing executives must adopt a zero-tolerance policy: break the trust once, and you never will write non-fiction again" (2004). And here's Lemann, dean of journalism at Columbia University:

A newspaper organization can change its incentive structure so that employees don't feel that the only thing really valued is what's known in the trade as a "holy shit!" story, and it can devise better ways to police itself. I have a suggestion for the Times and other big newspapers: establish a guerrilla team of fact checkers who perform random pre-publication reviews of a small percentage of stories. ... God is not going to stop making charismatic maniacs, so it falls to newspapers to figure out how to do a better job of apprehending them. (2004, 136ff)

To some extent, the change is already happening. "We Google everything now," said a senior executive from the Globe and Mail at a recent forum. But 
"Googling" is not the same as rigorous fact-checking, and so far, few newspapers are routinely engaged in the latter (Rosen, 2004.) Nor is fact-checking itself a magic bullet: Glass wrote for a magazine that considered itself scrupulously factchecked. So he didn't just cheat in print. He fabricated his own reporting notes; he fabricated a newsletter for a non-existent association of hackers; he fabricated websites. Like most magazine fact-checking, The New Republic's system had loopholes: the checkers did not insist on talking to the people whom Glass had allegedly interviewed. And, as Glass said in the 60 Minutes interview, fabricated people don't write in to complain.

In other words, at the crudest level, Glass, and Blair, and all the others, did it because they could. Maybe that's the overriding message of the cheating cultureand the thing that most urgently needs to change.

\section{References}

Freedman, Samuel G. (2004, March 24). Don't reward deceitful writers. USA Today, p. A13.

Lemann, Nicholas. (2004, March 15). Blair house: The wayward press. The New Yorker, $80,136 \mathrm{ff}$.

Patterson, Margaret Jones, \& Urbanski, Steve. (2004). What Jayson Blair and Janet Cooke say about the press and the erosion of public trust. Paper presented at the Association for Education in Journalism and Mass Communication conference, Toronto, ON.

Rosen, Jill. (2004, June/July). We mean business. American Journalism Review, 22-29. URL: http://www.ajr.org/Article.asp?id=3668 [February 27, 2006].

Shafer, Jack. (2003, June 12). The fabulous fabulists: Mencken, Liebling, and Mitchell made stuff up, too. Why do we excuse them? Slate. URL: http://www.slate.com/id/ 2084316 [February 27, 2006]. 